\title{
Future strategies in treatment of parkinson's disease
}

\author{
K.H. Janbaz'1, M.I. Qadir ${ }^{2}$, F. Younas², M. Ali ${ }^{3}$, S.A. Malik ${ }^{4}$ \\ ${ }^{1}$ Department of Pharmacy, ${ }^{3}$ Institute of Biotechnology, Bahauddin Zakariya University, Multan, Pakistan, ${ }^{2}$ College of \\ Pharmacy, Government College University, Faisalabad, Pakistan, ${ }^{4}$ Department of Biochemistry, Faculty of Biological Sciences, \\ Quaid-i-Azam University, Islamabad, Pakistan
}

\begin{abstract}
Parkinson's disease (PD) is a neurodegenerative disorder. COMT inhibitors, MOA-B inhibitors, Levodopa, Levodopa in combination with Dopa Decarboxylase (DDC) inhibitors, Entacapone, Tolcapone, Pramipexole, Ropinirole, Zonisamide, Cholinesterase inhibitors such as rivastigmine, galantamine and donepezil are used for treatment of Parkinson's disease. Gene therapy of cellular and brain circuit pathways for the treatment of PD is under trials. Recently nuclear transfer embryonic stem cells or induced pluripotent stem derived cells can be used. The presence of Lewy bodies, reduced dopamine transporter and tyrosine hydroxylase expression within transplanted cells indicated that grafted cells are pathological. Adult and fetal neural stem cells are self-renewable.
\end{abstract}

Keywords: Parkinson's disease, levodopa, gene therapy.

\section{Current therapies}

Parkinson's disease is a neurodegenerative disorder. Many new strategies have emerged \& Parkinson disease (PD) symptoms have improved. Levodopa is the efficacious medication for Parkinson's disease (PD) but when we use levodopa continuously it will lead to motor fluctuation and other side effects. Catechol-o-methyl transferase (COMT) inhibitors enhance 'on' time and decrease 'off' time and improve motor fluctuation. Anticholinergics are used to treat tremor rigidity and urinary urgency. Monoamine oxidase-B (MOA-B) inhibitors e.g. selegiline provide

Correspondence: M. I. Qadir

E-mail: mrimranqadir@hotmail.com symptomatic improvement. Amantadine provides both symptomatic benefit $\&$ dyskinesia benefit in some patients. Selective dopamine blockers such as clozarin and quetiapine are useful in addition to levodopa and dopamine agonists. ${ }^{1}$ Transdermal rotigotine which is a dopamine agonist is also very effective. Deprenyl induce orthostatic hypotension through its amphetamine catabolites. Amantadine is used to treat dyskinesia in PD. ${ }^{2}$ Scientists are trying to minimize the side effects of Levodopa, and enhance CNS bioavailability. When Levodopa is given with DDC inhibitors it relieres the symptoms of Parkinson's disease. ${ }^{3}$ COMT is an enzyme that causes the metabolism of catecholamines. When we inhibit this enzyme, 


\section{Gene therapy for parkinson's disease}

In this section, we have discussed cellular and brain circuit pathways relevant to Parkinson's disease that would be clinically acquiescent to gene therapy. Two main categories, are descussed i.e. symptomatic vs. neuroprotective. ${ }^{17}$

Cell and gene therapies for Parkinson's disease

PD patients have mobility problems even we treat them with the most advantageous treatment, using drugs or neurosurgery. So many patients entail additional physical therapy. ${ }^{18}$ Six particular central areas were identified for physical therapy: transfers, posture, reaching and grasping, balance, gait, and physical capacity. ${ }^{19}$ To treat patients with neurological disease, we have to implant cell or transfer the genes. For selection and development of specific therapeutic cell stem cell and progenitor cell biology give new aspects. ${ }^{20}$ Neurons lost in the substantia nigra are replaced with normal dopaminergic cells to treat the patient with PD. Possible sources for cell therapy are fetal ventral mesencephalon tissue, autologous grafts of dopamine secreting cells, and stem cell types. Recently, induced pluripotent stem cells were used successfully to treat rodent Parkinson's disease models. ${ }^{21,22}$ Controlled clinical trials of fetal cell transplantation for PD have had disappointing results. ${ }^{23}$ In cell replacement therapy for Parkinson's disease, A9 neurons of the substantia nigra and the A10 neurons of the ventral tegmental area are present in grafts of foetal ventral mesencephalon which recovers the motor performance. ${ }^{24}$ The restorative capacity of fetal dopaminergic transplants is administered by graft location, survival of transplant neurons. So two implantation sites, the nucleus accumbens and the caudateputamen unit are investigated. ${ }^{25}$ When we transplant foetal dopamine neurons into the striatum of Parkinson's disease patients, restoration of the dopamine system occurs. But certain problem arises with cellular replacement. When we carefully prepare cellular suspensions it minimizes graftinduced inflammatory responses. We can place small cell deposits directly into the host substantia nigra, by using micro transplantation approach. ${ }^{26 \text {, }}$ ${ }^{27}$ Embryonic stem (ES) cells transplantation provide an unlimited supply of specific cell types with broad developmental potentials that were able to differentiate into dopaminergic neurons in a rodent PD model. However there is the danger of tumor formation. When stem cells are predifferentiated into dopaminergic neurons in vitro before implantation, the tumorigenic potential of ES cells is greatly reduced. ${ }^{28}$ However the ES cells are perfect cell source for transplantation because they seize huge quantity of the desired cell type. Adult and fetal neural stem cells are self-renewable and they do not have tumorigenic potential. Other cell sources for replacement are bone marrow stromal cells \& induced pluripotent stem cells. ${ }^{29}$ Embryonic stem cell-derived L1 overexpressing neural aggregates enhances neuronal migration and neurite outgrowth. ${ }^{30}$ Upcoming genetic material and cell therapies are expected to live together with standard effects of drug treatment for the reason that their application can be modified to individual patients' principal disease procedure and need for neuroprotective or curative interventions. In conclusion, regardless of a positive advancement of the cell tools in neurology, the approach still wants further research, which would allow 
K.H. Janbaz et al. Future strategies in treatment of parkinson's disease

15. C. Kim, S.J. Lee. Controlling the mass action of alphasynuclein in Parkinson's disease. J Neurochem 2008; 107:303-16.

16. F. Xu, J.H. Luo, J.H. Jin. Alpha-synuclein interacted proteins: the relevance with the pathogenesis of Parkinson's disease. Zhejiang Da Хие Хие Вао Yi Хие Ban 2008; 37:524-30.

17. G. Porras, E. Bezard. Preclinical development of gene therapy for Parkinson's disease. Exp Neurol 2008; 209:72-81.

18. S.H. Keus, M. Munneke, M.J. Nijkrake, et al. Physical therapy in Parkinson's disease: evolution and future challenges. Mov Disord 2009; 24:1-14.

19. S.H. Keus, B.R. Bloem, E.J. Hendriks, et al. Evidencebased analysis of physical therapy in Parkinson's disease with recommendations for practice and research. Mov Disord 2007; 22:451-60.

20. O. Isacson, J.H. Kordower. Future of cell and gene therapies for Parkinson's disease. Ann Neurol 2008; 64:S122-38.

21. Z. Ren, Y. Zhang. Cells therapy for Parkinson's disease_-so close and so far away. Sci China C Life Sci 2009; 52:610-4.

22. G.R. Laguna, P. Tyers, R.A. Barker. The search for a curative cell therapy in Parkinson's disease. J Neurol Sci 2008; 265:32-42.

23. B. Roitberg, K. Urbaniak, M. Emborg. Cell transplantation for Parkinson's disease. Neurol Res 2004; 26:355-62.

24. S. Grealish, M.E. Jönsson, M. Li, et al. The A9 dopamine neuron component in grafts of ventral mesencephalon is an important determinant for recovery of motor function in a rat model of Parkinson's disease. Brain 2010; 133:482-95.
25. C. Rosenthal, T. Reum, R. Morgenstern, et al. Pattern of long-term sensorimotor recovery following intrastriatal and accumbens DA micrografts in a rat model of Parkinson's disease. J Comp Neurol 2009; 515:41-55.

26. E. Hedlund, T. Perlmann. Neuronal cell replacement in Parkinson's disease. J Intern Med 2009; 266:358-71.

27. L.H. Thompson, S. Grealish, D. Kirik, et al. Reconstruction of the nigrostriatal dopamine pathway in the adult mouse brain. Eur J Neurosci 2009; 30:62538.

28. Y. Luo, S.Y. Kuang, B. Hoffer. How useful are stem cells in PD therapy? Parkinsonism Relat Disord 2009; 15:S171-5.

29. A.K. Meyer, M. Maisel, A. Hermann, et al. Restorative approaches in Parkinson's Disease: which cell type wins the race? J Neurol Sci 2010; 289:93-103.

30. Y.F. Cui, G. Hargus, J.C. Xu, et al. Embryonic stem cell-derived L1 overexpressing neural aggregates enhance recovery in Parkinsonian mice. Brain 2010; 133:189-204.

31. M.V. Ugriumov, A.N. Konovalov, E.I.Gusev. Results and outlooks of using cell technologies in the treatment of neurological diseases. Vestn Ross Akad Med Nauk 2004; 11:8-17.

32. R. Wijeyekoon, R.A. Barker. Cell replacement therapy for Parkinson's disease. Biochim Biophys Acta 2009; 7:688-702.

33. Z. Ren, Y. Zhang. Cells therapy for Parkinson's disease—so close and so far away. Sci China C Life Sci 2009; 52:610-4.

34. M. Gerlach, H. Braak, A. Hartmann, et al. Current state of stem cell research for the treatment of Parkinson's disease. J Neurol 2002; 249: 33-5. 